\title{
Research article \\ Anti - inflammatory activity of ten indigenous plants in carrageenan induced paw oedema in albino rats
}

\author{
Manjula Shimoga Durgoji Raoㄹ, Sucheta Prasanna Kumar ${ }^{2}$, Vasanthalaxmi Krishnanada Rao ${ }^{1}$ \\ ${ }^{1}$ Associate Professor, ${ }^{2}$ Selection Grade Lecturer, Department of Physiology, Kasturba Medical College, Manipal Academy of \\ Higher Education, Manipal- 576104, Karnataka, India
}

(Received: April $2021 \quad$ Revised: August $2021 \quad$ Accepted: August 2021)

Corresponding author: Vasanthalaxmi K. Rao. Email: Vl.upadhya@manipal.edu

\begin{abstract}
Introduction and Aim: Inflammation is a symptom associated with many diseases, can be treated with steroidal and non-steroidal anti-inflammatory drugs, which can cause severe side effects when used as long-term treatments. Plants have the ability to synthesize a wide verity of phytochemical compounds as secondary metabolites which shows antiinflammatory activity. The anti-inflammatory activity of crude extracts of leaves of Jasminum grandiflorum (Jg), Vinca rosea (Vr), Azadirachta indica (Ai), Lawsonia inermis (Li), Nerium indicum (Ni), Calotropis gigantea $(\mathrm{Cg})$, Tectona grandis $(\mathrm{Tg})$, Andrographis paniculata (Ap), Tabernaemontana corymbosa $(\mathrm{Tc})$ and Marsedinia volubilis $(\mathrm{Mv})$ as well as alcoholic extracts of leaves of $\mathrm{Cg}$, $\mathrm{Tg}$ and $\mathrm{Ap}$ were evaluated in Wistar rats.
\end{abstract}

Methods: Acute anti-inflammatory activity of crude extracts of ten indigenous plants were studied by calculating the volume changes in the hind paw after injecting carrageenan in rats comparing with Ibuprofen which was used as a standard drug in this study. Anti-inflammatory effect of alcoholic extract of leaves of Ap, $\mathrm{Tg}$ and $\mathrm{Cg}(200 \mathrm{mg} / \mathrm{kg}$ body weight) also studied.

Results: The groups treated with crude extract \& alcoholic extract of $\mathrm{Cg}, \mathrm{Tg}$ and Ap showed significant reduction in the oedema compared to control and other plant extracts. The result was very significant in Ap treated rats.

Conclusion: Plants are one of the most important sources of medicines. In our study, the anti-inflammatory activity of ten indigenous plants could be due to presence of naturally occurring antioxidant flavonoids. The leaves of Ap are very rich in flavonoids, could be the reason for significant anti-inflammatory activity found in Ap treated rats.

Keywords: Indigenous plants, carrageenan, anti-inflammatory, Andrographis paniculata, rats

\section{INTRODUCTION}

$\mathrm{I}$ nflammation can be defined as the "reaction of vascularized living tissue to local injury." The main objective of inflammation is to dilute, delimit and possibly eliminate the foreign particles, microorganisms or antigens. It also helps in clearing the damaged site of dead cells and thereby initiating the way for wound repair (1). The healing process begins during the early phase of inflammation but usually reaches completion after the injurious influence had been neutralized. Acute inflammation is of relatively short duration lasting for a few minutes to several hours or even few days. The local clinical signs of acute inflammation are heat, redness, swelling and pain. When the noxious stimulant cannot be destroyed or eliminated by a process of acute inflammation, there will be development of signs and symptoms of sub-acute inflammation (2). These symptoms are treated with steroidal and non-steroidal antiinflammatory drugs, which can cause severe side effects when used as long-term treatments.
India is richly endowed with diverse medicinal plants with anti-inflammatory activities that have been shown to be effective in the treatment of inflammatory conditions in traditional medicine.

Plants are one of the most important sources of medicines. Since ancient time's medicinal plants have been used to treat different ailments due to their accessibility, availability, inherited practice, economic feasibility, and perceived efficacy. Research on plants with inflammatory activities is one of the developing areas in modern biomedicine

In our study, the anti-inflammatory activity of Crude extracts of 10 indigenous plants viz., Jasminum grandiflorum (Jg), Vinca rosea (Vr), Azadirachta indica (Ai), Lawsonia inermis (Li), Nerium indicum (Ni), Calotropis gigantea $(\mathrm{Cg})$, Tectona grandis $(\mathrm{Tg})$, Andrographis paniculata (Ap), Tabernaemontana corymbosa (Tc) and Marsedinia volubilis (Mv) (Figure 1) and alcoholic extracts of Andrographis paniculata, Calotropis gigantea and Tectona grandis, were studied in rats using carrageenan induced rat hind paw oedema model. 


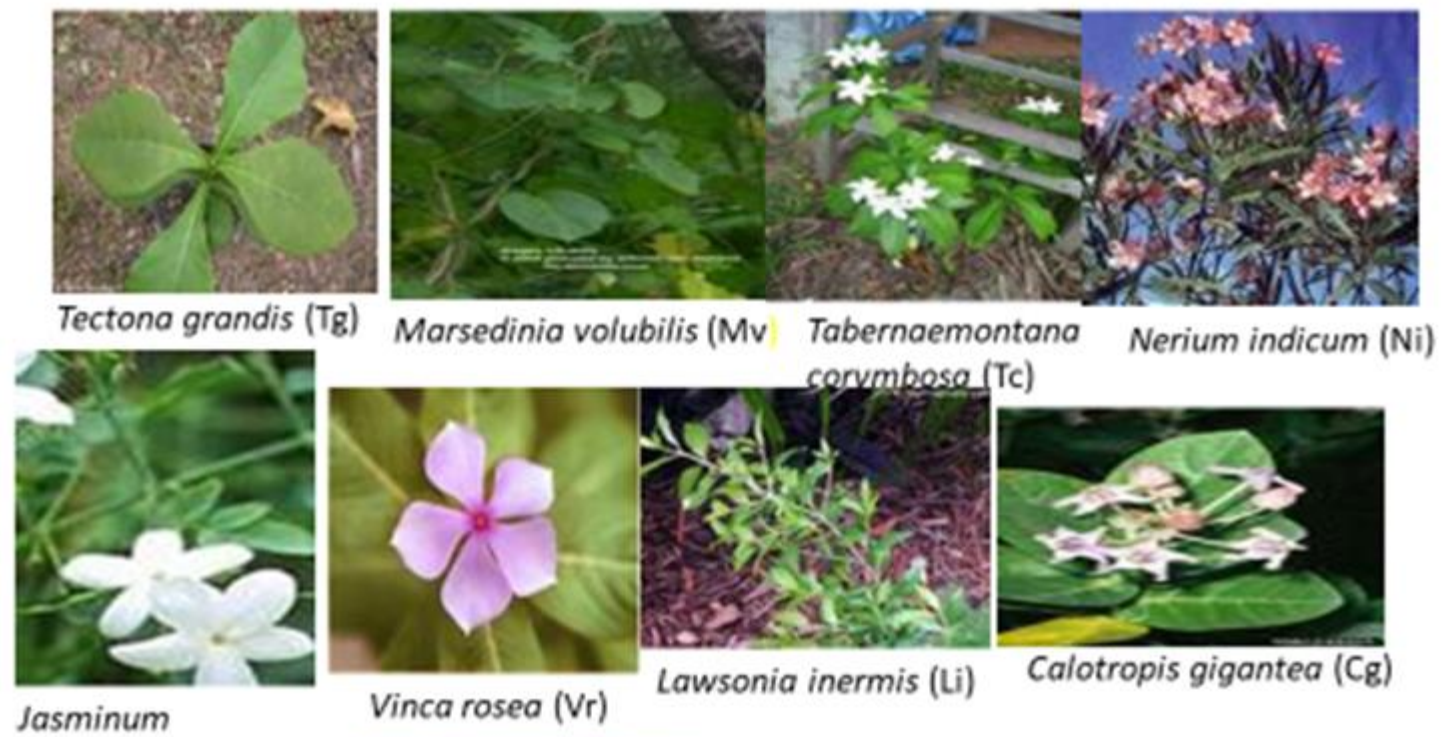

Jasminum
grandiflorum $(\mathrm{Jg})$

Vinca rosea $(\mathrm{Vr})$
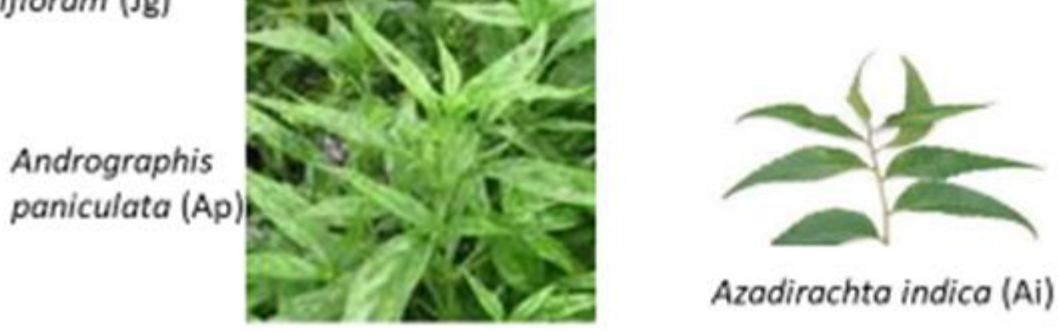

Azadirachto indica (Ai)

Fig. 1: List of selected indigenous plants

\section{MATERIALS AND METHODS}

\section{Animals}

Healthy adult albino rats of either sex (150-250 g) of Wistar strain were selected for this experiment. The animals were procured and maintained in the Central animal facility, Kasturba Medical College, Manipal Academy of Higher Education. These animals were maintained under controlled conditions of temperature $\left(28^{\circ} \pm 10^{\circ} \mathrm{C}\right.$ temperature and $50 \pm 5 \%$ humidity) and light in animal house having free access to water and standard pallet diet. All the experiments were performed in accordance with the approval and guidelines of Animal Ethics Committee of Kasturba Medical College Manipal, Manipal Academy of Higher Education.

The plants which are used for screening were collected in and around Udupi and Manipal during SeptemberJanuary and identified by Prof. Aravinda Hebbar, department of botany, M.G.M. College, Udupi.

\section{Experimental design}

\section{Preparation of crude extract}

Fresh leaves of the plants were collected, and the leaves were crushed with a mortar and pestle. The expressed juice was centrifuged. In our experiment, crude extracts of 10 indigenous plants were used. The volume of juice obtained for each plant is expressed as $\mathrm{ml} / 100 \mathrm{gms}$ of leaves. Dose used in the study is $2 \mathrm{ml} /$ $\mathrm{kg}$ body weight.

\section{Preparation of alcoholic extract}

Leaves were collected, dried in the shade, and powdered. The powder was used for preparation of extract. Leaf powder $(75 \mathrm{~g})$ was extracted with $700 \mathrm{ml}$ of $95 \%$ ethanol in a Soxhlet apparatus at $60-75^{\circ} \mathrm{C}(3)$. Extract was concentrated.

Acute edema model- Carrageenan induced paw edema model used.

Route of drug administration - Oral, 1 hour before inducing edema.

For screening of crude extract of 10 indigenous plants8 rats of either sex per group was used.

Group 1-control, treated with normal saline, group 1I - standard drug- Indomethacin. Group III-XI1-treated with crude extract of $\mathrm{Jg}, \mathrm{Ai}, \mathrm{Li}, \mathrm{Ni}, \mathrm{Vr}, \mathrm{Mv}, \mathrm{Tc}, \mathrm{Cg}$, Tg and Ap respectively.

Dosage: $2 \mathrm{ml} / \mathrm{kg}$ body weight.

For further screening, alcoholic extracts of $\mathrm{Cg}, \mathrm{Tg}$ and Ap - 8 rats of either sex per group was used. Group 1 - control, treated with normal saline, Group 1I standard drug, Group III-V -treated with $\mathrm{Cg}$, Tg and Ap respectively. Dosage $: 200 \mathrm{mg} / \mathrm{kg}$ body weight,

\section{Hind paw oedema model}

In this wound model, acute anti-inflammatory activity is studied by calculating the volume changes in the hind paw after injecting carrageenan. In this wound model, \% inhibition of oedema was measured. This was studied by the rat paw edema method by intraplantar injection of $0.05 \mathrm{ml}$ of $1 \%$ carrageenan solution into the right hind paw of the rat to induce edema. The zero-hour paw volume was measured using a water plethysmograph immediately after 
carrageenan injection. The paw volume was again measured after $3 \mathrm{hrs}$. The difference between the $3 \mathrm{hr}$ and $0 \mathrm{hr}$ values gives the edema volume due to acute inflammation caused by the carrageenan injection. The $\%$ inhibition of edema was calculated by

$\%$ Reduction in paw edema $=\frac{\mathrm{Vc}-\mathrm{Vt}}{\mathrm{Vc} \times 100}$

$\mathrm{Vc}=$ mean edema volume in control group

$\mathrm{Vt}=$ mean edema volume in drug treated animal.

\section{Statistical analysis}

Data obtained from all the above experiments were correlated and analyzed by one way Analysis of Variance (ANOVA) followed by Bonferroni's post- test wherever applicable using statistical software package, Graph Pad in Stat (GPIS) 1990: version 1.13. Values of $\mathrm{p}<0.05$ were considered statistically significant.

\section{RESULTS}

The rats treated with standard (Indomethacin), \% inhibition of oedema was $62.96 \%$.

The groups treated with crude extracts of $\mathrm{Vr}, \mathrm{Ai}, \mathrm{Li}$, $\mathrm{Cg}, \mathrm{Tg}$ and Ap showed significant reduction in the oedema $(48.14 \% ; 48.14 \% ; 46.29 ; 48.14 \% ; 48.14 \%$ and $51.85 \%$ respectively) compared to control group. But it was not very significant compared to standard treated rats (Fig. 1).

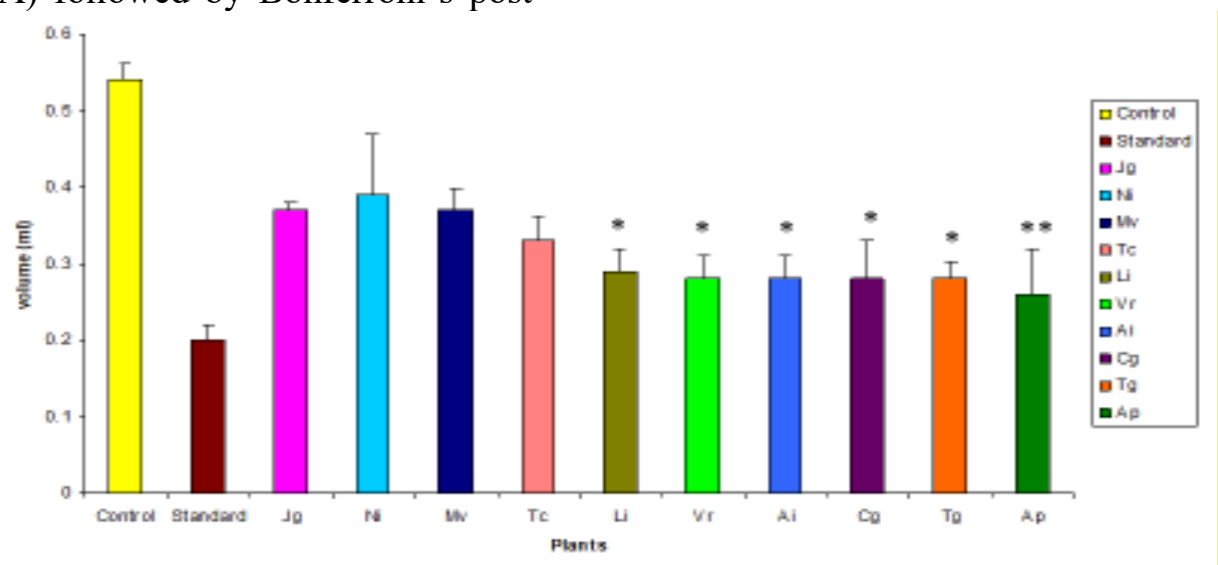

Fig. 1: Effect of standard drug and various indigenous drugs on acute inflammation.

Jg- Jasmimum grandiflorum; Ai- Azadirachta indica; Li- Lawsonia inermis; Ni- Nerium indicum; Vr- Vinca rosea; MvMarsedinia volubilis; Tc- Tabernaemontana corymbose; Cg-Calotropis gigantea; Tg- Tectona grandis; Ap- Andrographis paniculate. ${ }^{*} \mathrm{p}<0.05, * * \mathrm{p}<0.01, * * * \mathrm{p}<0.001 \mathrm{v} / \mathrm{s}$ control.

There was a significant decrease in oedema in alcoholic extracts of $\mathrm{Cg}(48.14 \%), \mathrm{Tg}(46.3 \%)$ and $\mathrm{Ap}$ $(51.9 \%)$ treated rats compared to control. Out of these 3 plants, significant result was found in Ap treated rats. From the above screening studies, crude and alcoholic extracts of Ap have shown significant antiinflammatory activity as compared to other plants (Fig. 2).

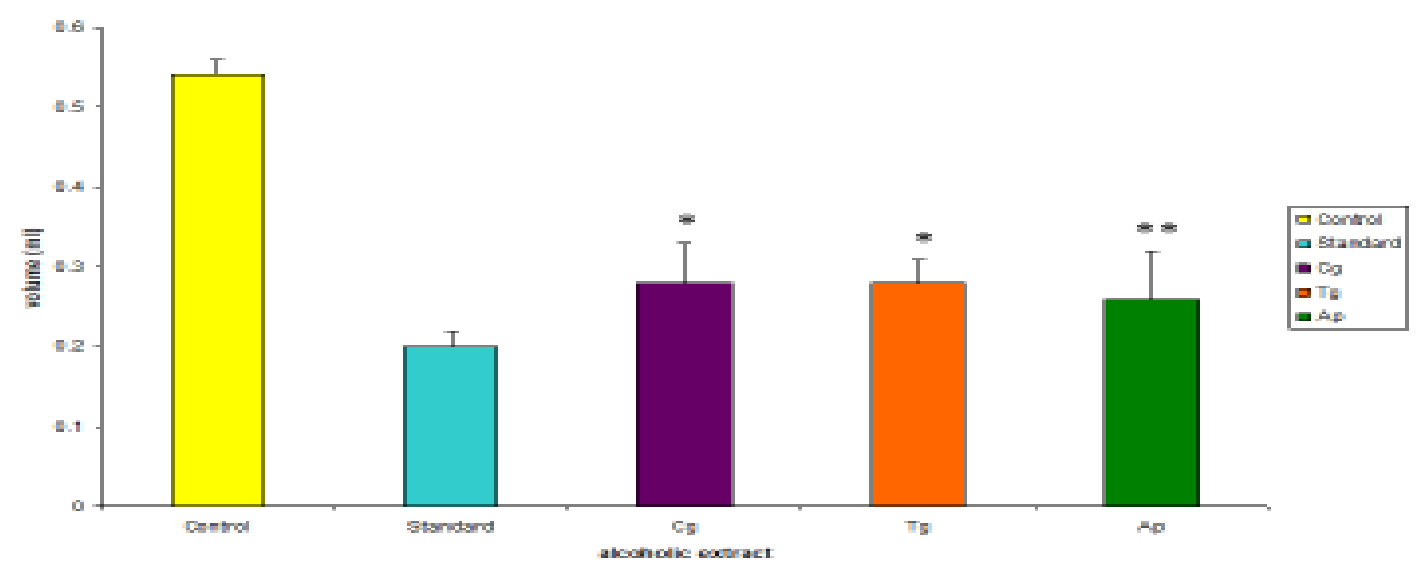

Fig. 2: Effect of standard and alcoholic extracts of $\mathrm{Cg}$, Tg, and Ap on acute inflammation

Cg- Calotropis gigantea; Tg- Tectona grandis; Ap- Andrographis paniculate. ${ }^{*} \mathrm{p}<0.05,{ }^{*} \mathrm{p}<0.01 \mathrm{v} / \mathrm{s}$ control.

\section{DISCUSSION}

Inflammation is a part of the body's immune response. Inflammation and tissue damage are due to the liberation of free radicals $(4,5)$. Plants have can synthesize a wide variety of phytochemical compounds as secondary metabolites which shows anti-inflammatory activity. In our initial screening study, the ten indigenous plants, Jasminum grandiflorum (Jg), Vinca rosea (Vr), Azadirachta indica (Ai), Lawsonia inermis (Li), Nerium indicum $(\mathrm{Ni})$, Calotropis gigantea $(\mathrm{Cg})$, Tectona grandis $(\mathrm{Tg})$, Andrographis paniculata (Ap), Marsedinia volubilis $(\mathrm{Mv})$ and Tabernaemontana corymbosa $(\mathrm{Tc})$ were mentioned in Ayurvedic textbooks and folklore medicine. These plants were selected on the basis of 
earlier reports and local reputation on antiinflammatory activity. There was a significant decrease in oedema induced by carrageenan in groups treated with crude extracts of $\mathrm{Ap}, \mathrm{Cg}, \mathrm{Tg}, \mathrm{Vr}, \mathrm{Li}$ and $\mathrm{Ai}$, compared to control. There are many plants having antiinflammatory activity. Some of the plants which have shown antiinflammatory activity, Andrographis paniculata (6), Ocimun sanctum (7), Loasa speciosa (8), Hemigraphis colorata (9), Bergenia ciliate sternb (10), Hyptis suaveolels (11), Hibiscus esculantus (12) and Benincasa hispida (13) were reported.

It has been reported that in acute inflammation, chemical mediators like 5-hydroxy tryptamine (5$\mathrm{HT}$ ), histamine, bradykinin and $\mathrm{PGE}_{1}$ are released. In $\mathrm{Ai}$ and $\mathrm{Cg}$ treated rats, it has been shown that the antiinflammatory activity is probably due to decrease in 5$\mathrm{HT}$ and $\mathrm{PGE}_{1}(14 \& 15)$. It was also reported, the acute inflammation is due to the releasing of chemical mediators like 5-hydroxy tryptamine (5-HT), histamine, bradykinin and $\mathrm{PGE}_{1}$ in groups treated with Andrographis paniculata (6). Most of the researchers concluded their study by mentioning that the antiinflammatory activity may be due to inhibition of the enzyme cyclooxygenase leading to inhibition of prostaglandin synthesis (16). Recent studies suggested the anti-inflammatory activity could be due to presence of naturally occurring antioxidant flavonoids (17) which scavenges the free radicals produced during inflammation.

Out of the 10 indigenous plants screened, the crude extracts of $\mathrm{Cg}, \mathrm{Tg}$, and $\mathrm{Ap}$ have shown significant results than other plants. Hence, further screening studies were also done with the alcoholic extracts of $\mathrm{Ap}, \mathrm{Cg}$ and Tg plants.

Rats treated with alcoholic extract of Ap has shown significant anti-inflammatory activity by decreasing \%inhibition of oedema compared to alcoholic extracts of $\mathrm{Cg}$ and $\mathrm{Tg}$.

Andrographis paniculata Nees is a medicinal plant belonging to the family of Acanthaceae, commonly called as Kalmegh is reported to be widely used by tribals all over India (18). Diterpenoids and flavonoids are the main chemical constituents of Ap and these compounds are believed to be responsible for the biological activities of the plant (19). Oral administration of extracts of Ap showed significant anti-inflammatory activity in pathogen induced PID rats (20). It was reported that extracts of Ap have antiinflammatory, antioxidant properties $(21,22)$.

\section{CONCLUSION}

Natural products are an alternative source of new compounds with anti-inflammatory activity. Plants are one of the most important sources of medicine as they have gained importance and popularity in recent years because of their safety, efficacy and cost effectiveness. In our study, the anti-inflammatory activity of these indigenous plants could be due to presence of naturally occurring antioxidant flavonoids.

\section{CONFLICT OF INTEREST}

There is no conflict of interest

\section{REFERENCES}

1. Dawson, W., Willoughby, D. A., Lambardino, J. G. Nonsteroidal anti-inflammatory drugs. New York: John Willey and Sons. 1985: 78-109.

2. Ryan, G. B., Majno, G. Acute inflammation. A review. Am J Pathol .1977; 86: 183-276.

3. Suffness, M., Douros, J. New natural products of interest under development at the national cancer Institute. Cancer Chemother Pharmacol. 1978; 1(2): 91-100.

4. Conner, E. M., Grisham, M. B. Inflammation, free radicals and antioxidants. Nutrition. 1996; 12: 274-277.

5. Garrido, G., Gonzalez, D., Lemus, Y., Garcia, D., Lordeiro, L., Quintero, G., et al., In vivo and in vitro anti-inflammatory activity of Mangifera indica L. extract (VIMANG®). Pharmacol. Res. 2004; 50: 143-149.

6. Amroyan, E., Gabrielian, E., Panossian, A., Wikman, G., Wangner, H. Inhibitory effect of Andrographolide from Andrographis paniculata on PAF-induced platelet aggregation. Phytomedicine. 1999; 6(1): 27-31.

7. Singh, S., Majumdar, D. K. Evaluation of anti-inflammatory activity of fatty acids of Ocimum sanctum fixed oil. Indian J Exp Biol. 1997 Apr; 35 (4): 380-383.

8. Badilla, B., Arias, A. Y., Arias, M., Mora, G. A., Poveda, L. J. Anti-inflammatory and antinociceptive activities of Loasa speciosa in rats and mice. Fitotherapia. 2003; 74: 45-51.

9. Subramonian, A., Evans, D. A. Effect of Hemigraphis colorata (Blume) H. G. Hallier leaf on wound healing and inflammation in mice. Indian J Pharmac. 2001; 33: 283-285.

10. Sanghamitra Sinha. Evaluation of anti-inflammatory potential of Bergenia ciliata sternb. Rhizome extract in rats. J Pharmac. 2001; 53: 193-196.

11. Shenoy, R., Shirwaikar. Anti-inflammatory and free radical scavenging studies of Hyptis suaveolens (Labiatae). Indian drugs. 2002; 39(11): 574-577

12. Tirupathy Kumareshan, P. R., Ananda Vijay Kumar, A., Rajasekaran. Anti-inflammatory activity of Hibiscus esculantus. Indian drugs. $2001 \mathrm{Aug} ; 38(8)$.

13. Chandra Babu, S., Umamagheshwari, S. Studies on the antiinflammatory activity of fruit rind extract of Benincasa hispida cogn. Indian drugs. 2002. Dec; 39(12): 651-653.

14. Chattopadhyay, R. R., Chattopadhyay, R. N., Maitra, S. K. Possible mechanism of anti-inflammatory activity of Azadirachta indica leaf extract. Indian J Pharmacol. 1993; 25(2): 99-100.

15. Kamath, J. V., Rana, A. C. Pharmacological activities of ethanolic extract of Calotropis procera roots. Indian Drugs. 2003 May; 40(5): 292-295.

16. Apurba, S. A., Shakhawat, H. B., Shamina, S. P., Md. Abdul Muhit. Anti-inflammatory activity of medicinal plants native to Bangladesh: A review. Journal of Applied Pharmaceutical Science. 2012; 02(02): 7-10

17. Havesteen, B. Flavonoids, a class of natural products of high pharmacological potency. Biochem Pharmacol. 1983; 32: 1141-1148

18. Chowdhury, A., Biswas, S. K., Raihan, S. Z., Das, J., Paul, S. Pharmacological potentials of Andrographis paniculata: An overview. International Journal of Pharmacology. 2012; 8(1): 6- 9.

19. Saxena, S., Jain, D. C., Rajendra, S., Bhakuni, R. S, Sharma, R. P. Chemistry and pharmacology of Andrographis Species. Indian drugs. 1998; 35(8): 458-467

20. Zou, W., Xiao, Z., Wen, X., Luo, J., Chen, S., Cheng, Z., et al. The anti-inflammatory effect of Andrographis paniculata (Burm. f.) Nees on pelvic inflammatory disease in rats 
through down-regulation of the NF- $\mathrm{B}$ pathway. BMC Complementary and Alternative Medicine. 2016; 16(483): 17.

21. Bukoye, O., Musbau, A., Adenike, O. In vitro and In vivo Evaluation of the antioxidant properties of aqueous extract of Andrographis paniculata leaves. Researcher. 2010; 2(11): 42- 51.

22. Verma, N., Vinayak, M. Antioxidant action of Andrographis paniculata on lymphoma. Mol Biol Rep. 2008; 35: 535- 540. 